\title{
Effect of Financial Capability on Customer Relationship Management in Private Hospitals in Kenya
}

Faithmercy Wanyi Muthigah, David Kiragu, Anne Sang

To Link this Article: http://dx.doi.org/10.6007/IJARBSS/v12-i1/12325

DOI:10.6007/IJARBSS/v12-i1/12325

Received: 14 November 2021, Revised: 17 December 2021, Accepted: 08 January 2022

Published Online: 28 January 2022

In-Text Citation: (Muthigah et al., 2022)

To Cite this Article: Muthigah, F. W., Kiragu, D., \& Sang, A. (2022). Effect of Financial Capability on Customer Relationship Management in Private Hospitals in Kenya. International Journal of Academic Research in Business and Social Sciences, 12(1), 2591-2599.

Copyright: (c) 2022 The Author(s)

Published by Human Resource Management Academic Research Society (www.hrmars.com) This article is published under the Creative Commons Attribution (CC BY 4.0) license. Anyone may reproduce, distribute, translate and create derivative works of this article (for both commercial and non0-commercial purposes), subject to full attribution to the original publication and authors. The full terms of this license may be seen at: http://creativecommons.org/licences/by/4.0/legalcode

Vol. 12, No. 1, 2022, Pg. $2591-2599$

Full Terms \& Conditions of access and use can be found at http://hrmars.com/index.php/pages/detail/publication-ethics 


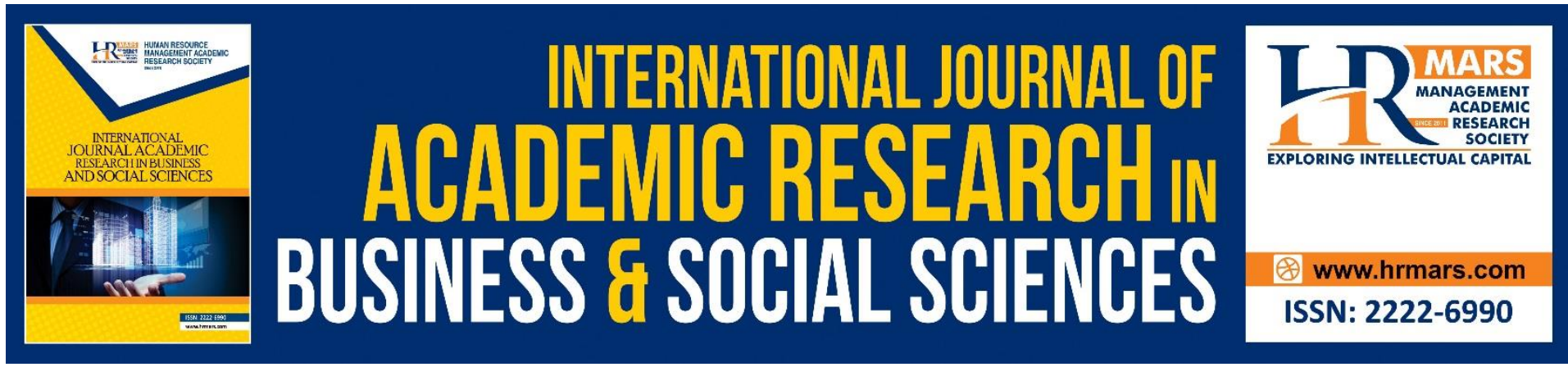

\title{
Effect of Financial Capability on Customer Relationship Management in Private Hospitals in Kenya
}

\author{
Faithmercy Wanyi Muthigah, Prof. David Kiragu, PhD, Dr. Anne \\ Sang $\mathrm{PhD}$ \\ Dedan Kimathi University of Technology \\ Corresponding Author Email: fmuthigah@gmail.com
}

\begin{abstract}
The purpose of this study was to establish the effect of financial capability on customer relationship management in private hospitals in Kenya. The study adopted descriptive survey design. It targeted 161 private hospitals which are accredited by NHIF in Kenya and which formed the unit of analysis of the study. Simple random sampling was then be used to obtain the 644 respondents. The researcher utilized a structured questionnaire with a five-point Likert scale to gather the data. The collected data was coded and entered in SPSS for further analysis. Descriptive and inferential analysis was conducted. The findings indicate there was a statistical and significant relationship between financial capabilities and customer relationship management. Financial capabilities explained $48.5 \%$ of the variability in customer relationship management in private hospitals. Hospitals should plan ahead forecast on financial emerging issues to avoid financial distress. Good governance is critical in an organization because it enables flexible adjustments to the emerging spending patterns as strategic demands arise
\end{abstract}

Keywords: Financial Capabilities, Customer Relationship Management,Private Hospitals

\section{Introduction}

Financial capabilities refers to combination of the human attitude, knowledge, understanding, motivation, confidence and skills that result in an organization having operational, managerial and financial stability in order to fulfil its purpose and deliver its results in line with its strategic objectives (Adeyemi, 2011). Financial capability has four distinct aspects: planning ahead, managing money, making choices and getting help through external or internal help. Financial capability of the firm is critical in implementation of the firms' strategies. Achieving desired financial outcomes requires the firm to accurately balance its expenditure and within the limitations of its income stream. Additionally, financial operational management in conjunction with effective governance is critical and enables precision in financial forecast and monitoring of the financial emerging issues. In that regard, financial budgets and plans of an organization should be flexible enough to enable adjustments to the emerging spending patterns as strategic demands arise. 
According to Memba \& Nyanumba (2013), main causes of financial distress in firms are factors which can be controlled by the firms as compared to the external factors which are difficult to control. These factors include financial structure (Total liabilities/ Total assets), cash flow ratio (Total Liabilities/net cash flow from operations) and leverage ratio (Debt/Equity) which influence the financial performance of the firm and can be used as indicators of the financial capability of the organization.

Adeyemi (2011) describes financial distress of the organizations as the main driver of failed strategies. He defines the financial distress as the condition in which an organization is having managerial, financial and operational difficulties. In that regard, financial capability can affect the implementation of CRM practices in an organization. Gongera, Ouma and Were (2013) evaluated the impact of financial risk on profitability of firms in Kenya. The outcomes showed a significant negative correlation between the liquidity risk level of the company and the profitability of the company and a strong, positive correlation between the risk management efficiency and profitability of the company. This study adapts the same logic to investigate the influence of financial capability of private hospitals on the CRM activities.

There are few studies which have been conducted on the financial capability and CRM or strategy adoption. Wang and Kung (2012) conducted a study to investigate the measurements, antecedents and consequences of CRM capabilities. The study utilized mixed study methodology integrating both quantitative and qualitative methodologies. A survey questionnaire was utilized in data gathering and hypotheses were examined using structural equation modelling. The study established significant effect of financial capabilities on CRM. The study results also hypothesized the influence of customer-centred organizational system and CRM technology on both CRM and CRM performance capabilities. The paper addressed different gaps in existing literature and took a look at CRM and developed a valid CRM measurement model.

Dous et al (2014) investigated financial and knowledge management capabilities in CRM. The study employed a case study methodology and derived a conceptual framework for successfully implementing financial capabilities and knowledge based capabilities in CRM initiatives. The study identified financial capabilities and knowledge management capabilities as very crucial for the success of CRM. Particularly, financial capabilities provided possible hurdles for the implementation of knowledge management on CRM and overall implementation of CRM.

Additionally, Kingstone (2014) investigated the financial realities of CRM to come up with framework guide to best practice. The study used explanatory research design which was allowed by inductive research philosophy. The study established cost as one of the main drivers for adopting CRM. The costs cut across software license fees to traditional enterprise CRM products delivered by Siebel, SAP, and PeopleSoft among others. Additionally, the complexity revolving issues such as configuration was found to create barriers to application of CRM. Finally, the study established perceived risk as past CRM failure from highly visible organizations. The study provided recommendations on basic buying criteria which eased the cost of CRM implementation. As such the study recommended very small IT staff and budgets in the sense that the basic CRM user often has to wear multiple hats in finance, IT and administration.

Although the reviewed studies attempted to link financial capability with CRM, they were conducted either in Europe or Asia and therefore presenting a geographical gap. Wang and Kung (2012) investigated the effect of financial resource on CRM strategy in Taiwan, while Dous et al (2014) examined the effect of financial knowledge on CRM in Germany and 
Switzerland and Kingstone (2014) investigated the financial realities in CRM in Europe. The studies only looked at few constructs of financial capabilities and therefore ignored other constructs which may affect CRM strategy. This thesis tried to fill this gap in this respect by studying financial capabilities as a driver of CRM in private hospitals in Kenya. This research then hypothesized a positive relationship between financial capacity and CRM. The study therefore tested the null hypothesis that stated that there was no significant relationship between financial capacity and CRM to validate the hypothesis of the research.

\section{Statement of the Problem}

Global health statistics report on monitoring health for SDGs indicated that weak and poor health systems remain a hindrance to progress resulting in insufficient in coverage for the most basic health services. Additionally, the AU Agenda 2063 states that, the main challenge in healthcare system is that, Africa countries lack advanced modern technology and informatics tools. In Kenya, the vision 2030 and big four agenda aim to attain universal health coverage that is accessible and affordable as well as safe medicines and vaccines for all. The government intends to upscale insurance scheme to all Kenyans to increase the universal health coverage through NHIF registration. This however remains a challenge and a complex task.

All these statistics demonstrate a gap in the industry, owing to the government's effort to fund and improve health standards of Kenya. The new millennium is in the centre of volatile transformation, witnessing expeditiously dynamic market environment, explosive equity markets, modernized value chains and advanced global competitors. Customer needs and preferences have as well changed and customer loyalty in the sustainable competitive business world is no longer a priority and has been replaced by CRM concept. Long-term success calls for lucrative CRM strategy to meet customer-oriented objectives, and as such organizations are making CRM their first priority. Hospitals are not an exceptional and are show casing their capabilities to gain competitive advantage in today's unstable economy. Being the vehicles used by the government in delivering healthcare services to the people, these hospitals can contribute to the agenda through effective CRM/ PRM, to increase health coverage and improve health standards. Enhanced management of customer relationship in healthcare organizations is an important component in meeting customers' demands and therefore attracting, maintaining, retaining and building customer loyalty.

Literature from different studies shows that the Kenyan hospitals' information system applications (such as hospital automation, electronic database and patient information) gather data entirely from hospital staff's viewpoints. Study done by Kathini (2012), in Mbagathi hospital found out that staff were not experienced in CRM practices. Yung et.al (2018) did a study on CRM Systems adoption in hospitals and concluded that CRM is influenced by hospital size, complexity and compatibility. These studies failed to determine factors that contribute to low CRM adoption in hospitals as well as determine the extent of implementation. Lack of customer feedback denies hospitals the opportunity to learn the needs, aspirations and contribution of a crucial mass in their value chain. Thus decisionmaking may be based on incomplete and skewed information that may lead to waste, inefficiency, ineffectiveness and in worst case scenario poor management practices.

There is uncertainty regarding exactly what CRM is, the best way to implement it, or its role in improving customer interaction. Based on this background, this study aimed to investigate the factors driving the adoption of financial capabilities in private hospitals in Kenya, by examining those that hospitals should prioritize when adopting customer relationship 
management to improve management of patient relationship in health care system, and specifically in private hospitals in Kenya.

\section{Methodology}

The study adopted descriptive survey design. The target population for this study was all private hospitals in Kenya. The sampling frame for this study was all 270 NHIF in-patient accredited private hospitals in Kenya. The study applied the multi-stage sampling procedure. A sample of 161 hospitals was considered as unit of observation. To get as accurate results as possible, four respondents on management level with the knowledge of the areas of the study were selected from each facility. They were identified as; the hospital superintendent, ICT manager, HR manager and accounts manager. This gave a total of six hundred and fourty four (644) respondents. The researcher utilized a structured questionnaire with a five-point Likert scale to gather the data. The collected data was coded and entered in SPSS for further analysis. Descriptive and inferential analysis was conducted. Before inferential analysis was conducted, diagnostics tests were done. Descriptive statistics (frequencies, mean scores, and standard deviations) were used to describe the characteristics of the variables. Descriptive statistics provide the basic features of the data collected. Inferential statistics was used to conclude the findings of test done on a population by taking a sample of information from the large population. The inferential statistic techniques were used to measure the significance of the relationship while the bivariate regression was employed to to evaluate the role of financial capabilities in customer relationship management in private hospitals in Kenya. In addition, a variance analysis (ANOVA) was presented. The results of the study were presented using tables, cross tabulation, frequency and percentage.

\section{Results}

\section{Descriptive statistical Analysis Results}

Descriptive Analysis for Financial capability

The study sought to assess the effect of financial capability on customer relationship management in private hospitals in Kenya. Statements on Financial capability were measured using a five point likert scale with the following equivalences; 1 - strongly disagree, 2 disagree, 3 - Neutral, 4 - Agree and 5 - Strongly Agree. Results are presented in Table 1.

Table 1: Descriptive Analysis results for Financial Capabilities

\begin{tabular}{|c|c|c|c|c|c|c|c|c|}
\hline & Statements & $\begin{array}{l}\text { SD } \\
\%\end{array}$ & $\begin{array}{l}\text { D } \\
\%\end{array}$ & $\begin{array}{l}\mathbf{N} \\
\%\end{array}$ & $\begin{array}{l}\text { A } \\
\%\end{array}$ & $\begin{array}{l}\text { SA } \\
\%\end{array}$ & Mean & S.D \\
\hline FC1 & $\begin{array}{l}\text { The hospital is able to finance its overall } \\
\text { operations from internally generated funds. }\end{array}$ & 0 & 14 & 14 & 40 & 32 & 3.90 & 1.01 \\
\hline FC2 & $\begin{array}{l}\text { The hospital is able to meet its financial } \\
\text { obligations. }\end{array}$ & 0 & 13 & 19 & 36 & 32 & 3.87 & 1.01 \\
\hline FC3 & $\begin{array}{l}\text { The hospital can pay off current debts with } \\
\text { cash generated within the same period. }\end{array}$ & 0 & 14 & 17 & 37 & 32 & 3.86 & 1.02 \\
\hline FC4 & $\begin{array}{l}\text { Stakeholders get dividends from profits of } \\
\text { the amount invested }\end{array}$ & 0 & 9 & 16 & 37 & 38 & 4.04 & 0.96 \\
\hline \multirow[t]{2}{*}{ FC5 } & $\begin{array}{l}\text { The hospital is generating just enough } \\
\text { revenue to pay for its fixed costs. }\end{array}$ & 0 & 13 & 11 & 43 & 33 & 3.96 & 0.98 \\
\hline & Overall & & & & & & 3.93 & 1.00 \\
\hline
\end{tabular}


From the results, highest mean was 4.04 with the statement that stakeholders get dividends from profits of the amount invested, where $75 \%$ of the respondents agreed with the statement. The high mean can be attributed to the fact that private hospitals are owned by individuals or group of individuals, who are majority shareholders and therefore they had to get returns from their businesses since business is about getting returns. The second highest mean was 3.96 with the statement that private hospitals were generating just enough revenue to pay for its fixed costs. Majority of the respondents at $76 \%$ agreed that internal funds generated by their respective hospitals alone were not adequate to fund for other needs, as $72 \%$ of the respondents also agreed that their respective hospitals were only able to finance overall operations from internally generated funds, statement which had the third highest mean of 3.90 .

The second lowest mean was 3.87 with the statement that the hospitals were able to meet their financial obligations. This implies that hospitals have to source for funding in order to remain in business as well as be able to finance other activities. Finally, the lowest mean was 3.86 with the statement that the hospitals could pay off their current debts with cash generated within the same period. This means that hospitals could not entirely rely only on the internally generated funds.

The overall mean score was 3.93. This value implies that a majority of the respondents agreed to the statements measuring financial capability role as a driver of customer relationship management. The Table further shows that standard deviation of all the measures of financial capability was 1.00. This value indicates that a large number of respondents agreed that financial capability driver was crucial in supporting CRM through funding in their respective hospitals. The findings of the study support studies by Dous et al (2014) which identified financial capabilities and knowledge management capabilities as very crucial for the success of CRM and Kingstone (2014) which investigated the financial realities in CRM in Europe and recommended budgeting as an important tool in administration.

\section{Inferential Analysis of Financial Capability on CRM}

The study sought to assess effect of financial capability on customer relationship management in private hospitals in Kenya. A simple regression model was used to test the statistical significance of the independent variable (financial capabilities) on the dependent variable (customer relationship management) in private hospitals in Kenya. The null hypothesis was:

\section{Ho4: Financial capability does not have a statistically significant effect on customer relationship management in private hospitals in Kenya.}

To test the hypothesis, model CRM $=\alpha+\beta_{4} \mathrm{X}_{4}+\varepsilon$ was fitted and results are presented in Table 2.

Table 2: Model Fitness of Financial Capabilities

\begin{tabular}{lllll}
\hline Model & R & R Square & Adjusted R Square & Std. Error of the Estimate \\
\hline 1 & $.697 a$ & 0.486 & 0.485 & 0.27763 \\
\hline
\end{tabular}

Results show that $\mathrm{R}^{2}=0.486$ implying that about $49 \%$ variation in customer relationship management is explained by the management of Financial Capability. This average performance can be attributed to the fact that most private hospitals were not able to fully finance their operations through the internally generated funds and mostly they were relying on borrowing from financial institutions. Factors such as total liabilities exceeding the total 
assets may have contributed to heavy borrowing. The model failed to account for $51 \%$ of the variation in CRM. This indicates that there are other factors associated with CRM which were not expounded by the model such as depreciation of assets.

In addition, this study did not consider disaster preparedness and management in case of an epidemic outbreak. The research was done during the corona pandemic and most hospitals were not prepared for the disaster as most of them had not set aside emergency funds.

Table 3: ANOVA for Financial Capability

\begin{tabular}{llllll}
\hline & Sum of Squares & df & Mean Square & $\mathbf{F}$ & Sig. \\
\hline Regression & 34.898 & 1 & 34.898 & 452.755 & $.000^{\mathrm{b}}$ \\
Residual & 36.921 & 479 & 0.077 & & \\
Total & 71.82 & 480 & & & \\
\hline
\end{tabular}

ANOVA was used to check the residual variance is reduced by predictors in regression model and the overall model significance. The linear regression $\mathrm{F}$ statistics presented in Table 4.23 shows that there was a statistical and significant linear relationship between financial capabilities and customer relationship management in private hospitals $F(1,480)$ $=452.755, p=0.000<.05)$. The $p=0.000<.05$ was less than 0.05 and thus implied that the overall model was statistically significant.

Table 4: Regression Coefficients for Financial Capability

\begin{tabular}{llllll}
\hline & \multicolumn{3}{l}{ Unstandardized Coefficients } & \multicolumn{3}{l}{ Standardized Coefficients } \\
& B & Std. Error & Beta & t & Sig. \\
\hline (Constant) & 3.469 & 0.035 & & 99.333 & 0.000 \\
Financial Capabilities & 0.228 & 0.011 & 0.697 & 21.278 & 0.000 \\
\hline
\end{tabular}

The regression coefficients presented in Table 4 shows that financial capabilities had a statistically and significantly effect on the CRM in private hospitals $(\beta=0.697, t=$ $21.278, p<.05)$. Given the ANOVA of 0.000 and financial capability had a P-value of 0.000 which was $<0.05$, the study thus, rejected the null hypothesis and adopted the alternative hypothesis that financial capability has a statistically significant effect on customer relationship management in private hospitals in Kenya

The estimated regression equation is given by:

$$
C R M=3.469+0.228 * \text { Financial Capabilities }
$$

It was evident from the descriptive analysis that majority of shareholders of private hospitals in Kenya were getting returns of their investments with $75 \%$ of respondents agreeing that, stakeholders were getting dividends from profits of the amount invested. This implies that as private hospitals efficiently rewarded their stakeholders, CRM becomes more effective as most of them would support it. The results are similar to Kingstone (2014) who established that cost as one of the main drivers for adopting CRM. The costs cut across software license fees to traditional enterprise CRM products delivered by Siebel, SAP, and PeopleSoft among others. Wang and Kung (2012) established significant effect of financial capabilities on CRM. The findings also corroborate with findings of study by Dous et al (2014) which identified financial capabilities and knowledge management capabilities as very crucial for the success of CRM. Particularly, financial capabilities provided possible hurdles for the implementation of knowledge management on CRM and overall implementation of CRM. Further, the findings support outcome of a study by Memba \& Nyanumba (2013), which concluded that the main causes of financial distress in firms are factors which can be controlled by the firms as 
compared to the external factors which are difficult to control. However, the findings of this study differ with findings in a study by Gongera et al (2013) about the Effects of Financial Risks on Profitability of Sugar Firms in Kenya. The outcomes of the study showed a significant negative correlation between the liquidity risk level of the company and the profitability of the company, meaning that the study did not find financial capability as a factor that can hinder CRM.

\section{Summary, Conclusions and Recommendations Summary}

The findings indicate there was a statistical and significant relationship between financial capabilities and customer relationship management. Therefore, the null hypothesis $\left(\mathrm{HO}_{1}\right)$ : financial capability does not have a statistically significant effect on customer relationship management in private hospitals in Kenya was rejected. Financial capabilities explained $48.5 \%$ of the variability in customer relationship management in private hospitals. These findings are supported by argument held by Dous et al (2014) that financial capabilities provided possible hurdles for the implementation of knowledge management on CRM and overall implementation of CRM rejecting the null hypothesis.

\section{Conclusion}

The study concluded that the hospitals were able to finance its overall operations from internally generated funds. The hospital is able to meet its financial obligations. The hospitals can pay off current debts with cash generated within the same period. Stakeholders get dividends from profits of the amount invested. The hospitals are generating just enough revenue to pay for its fixed costs.

\section{Recommendations}

The study recommends that hospitals should plan ahead forecast on financial emerging issues to avoid financial distress. Good governance is critical in an organization because it enables flexible adjustments to the emerging spending patterns as strategic demands arise.

\section{References}

Adeyemi, B. (2011). Bank failure in Nigeria: a consequence of capital inadequacy, lack of transparency and non-performing loans? Banks and Bank Systems, 6(1)

Dous, M., Salomann, H., Kolbe, L,. and Brenner, W. (2014), Knowledge Management Capabilities in CRM: Making Knowledge For, From and About Customers Work. 11th Americas Conference on Information Systems, Omaha, NE, USA 11th-14th 2014.

Gongera, E. G., Ouma, B. O., \& Were, J. N. (2013). The Effects of Financial Risks on Profitability of Sugar Firms in Kenya. European Journal of Business and Management.5 (3), 124-135.

Kathini, E. (2012), Utilization levels of computerized physician order entry (CPOE) by health care workers in Mbagathi District Hospital Nairobi Kenya. IOSR Journal of Nursing and Health Science (IOSR-JNHS)Vol.

Kingstone, Z. (2014). The Impact of Customer Relationship Management on Customer Satisfaction in the Banking Industry -A Case of Jordan. European. Journal of Business and Management www.iiste.org ISSN 2222-1905 (Paper) ISSN 2222-2839 (Online)Vol.6, No.32, 2014 
Memba, F., \& Nyanumba, J. (2013). Causes of financial distress: A survey of firms funded by Industrial and Commercial Development Corporation in Kenya. Interdisciplinary Journal of Contemporary Research in Business, 4(12), 11711185.

Wang, Y., Kung, L., \& Byrd, T. A. (2018). Big data analytics: Understanding its capabilities and potential benefits for healthcare organizations. Technological Forecasting and Social Change, 126, 3-13. 